\title{
DIPLOMACIA MIDIÁTICA E OS TEMAS DA AGENDA INTERNACIONAL NOS NOTICIÁRIOS DAS REVISTAS DE GRANDE CIRCULAÇÃO DO BRASIL - ESTUDO DE CASO NAS REVISTAS VEJA E ÉPOCA NO PRIMEIRO SEMESTRE DE 2018
}

\author{
Marco Paulo Bastos Souto Vieira Sales ${ }^{1}$
}

\begin{abstract}
Resumo
Este trabalho parte de uma reflexão acerca das notícias internacionais publicadas nas revistas de informação de grande circulação no Brasil: Veja e Época ao longo do primeiro semestre de 2018. Para delimitar o conteúdo desses periódicos, a seleção de materiais observados foram aqueles publicados nas editorias internacionais, porém as notícias que contextualizavam os Estados estrangeiros e referenciavam situações econômicas, sociais e ambientais também fizeram parte do recorte. Outro ponto delineado é a modalidade da diplomacia midiática que alguns autores apontam essa ferramenta como uma novidade na Política Externa para interferir nas publicações de conteúdo estrangeiro em outro território com abordagem de interesse hegemônico.

O estudo consistiu ainda em compreender os motivos pelos quais a imprensa do Brasil noticia acontecimentos em determinadas partes do mundo e em algumas situações exclui os fatos que ocorrem em outros países. A pesquisa busca também entender os impactos dessas notícias aos brasileiros com uma metodologia de coleta de informações quantitativa e exploratória.
\end{abstract}

Palavras-chaves: Diplomacia Midiática; temas da agenda internacional; política externa; jornalismo; jornalismo internacional; imprensa estrangeira; Veja; Época;

\footnotetext{
${ }^{1}$ Graduado em Comunicação Social/Jornalismo pela Faculdade Interamericana de Porto Velho (Uniron), com especialização em Metodologia Científica do Ensino Superior pela Faculdade Porto, e Graduando em Relações Internacionais pelo Centro Universitário Internacional (Uninter). E-mail: salemarco@gmail.com
} 


\section{Introdução}

A comunicação tem se tornado uma poderosa ferramenta para desenvolver estratégias na condução da Política Externa dos Estados. A globalização tem transformado o mundo de forma contínua e as interações entre os atores do mundo globalizado tem se potencializado cada vez mais de forma acelerada e dinâmica, o que torna fundamental a manutenção das relações internacionais.

Para CARVALHO (2015) a mídia exerce importante papel nos processos de globalização, revolução tecnológica e democratização ao se transformar em agente operacional e mediadora das relações produtivas e sociais. Isso significa que obter o domínio da comunicação colabora para o surgimento de novos ideais no ordenamento do capitalismo globalizado e a manutenção de hegemonias. As mídias influenciam de forma direta e indireta na política, isso se observa nas relações do Estado e dos grandes grupos empresariais que controlam as corporações midiáticas.

Enquanto que BURITY (2013) classifica a diplomacia midiática como um campo que analisa os efeitos dos modernos meios de comunicação e da imprensa sobre os assuntos de Estado em Política Externa e que trata também da interferência desses novos meios na agenda internacional e na disputa pelo poder. O que reforça a utilização dessa ferramenta por parte dos governos como estratégia para gerar pautas positivas no campo político perante a opinião pública. O Estado se torna aliado da mídia ao oferecer informação que tenha um interesse subliminar para os veículos de comunicação e dessa forma se estabelece a relação governo e mídia.

Desta forma, os jornalistas considerados apenas como intermediadores da informação, acabam por influenciar os assuntos de Estado em política externa ao divulgar as mensagens de interesse governamental de forma disfarçada, interferindo no jogo de disputas de poder internacional e contribuindo para a formação da opinião pública.

O fim da Guerra Fria proporcionou profundas transformações no que diz respeito à ordem política, econômica e na interação entre os Estados se fazendo presente também na política mundial com a criação de fóruns para a discussão de assuntos pertinentes aos interesses globais e negociações comerciais e de segurança.

\footnotetext{
Podemos citar a dinamização das trocas econômicas, a modernização das comunicações e dos meios de transporte, a ampliação dos contatos entre os povos em termos sociais, o agravamento da preocupação com o meio ambiente, os direitos humanos e as negociações comerciais.

Além disso podemos apontar avanços nas negociações de tratados para as áreas de desenvolvimento, cooperação internacional, combate à fome e à pobreza e desarmamento (PECEQUILO, 2017, p.

21)
}

Isso permite afirmar que os temas da agenda internacional do Brasil e do mundo podem se classificar de acordo com os seguintes assuntos: a segurança, o desenvolvimento, a cooperação econômica, técnica e científica, o meio ambiente e os recursos naturais, a fome e a segurança alimentar (VIANA, 
2017). Os noticiários do Brasil costumam trazer informações do exterior caracterizando cada país de acordo com alguns assuntos referentes a esses temas.

Portanto é importante entender o foco dos noticiários internacionais na grande mídia impressa e os motivos que levam aos acontecimentos em determinados países a receberem mais destaque e ocupando maior espaço nas revistas Veja e Época do que outros Estados. Da mesma forma, vale a pena compreender o grau de discussão sobre os assuntos de interesses globais no conteúdo das revistas e de que maneira a política internacional em determinadas partes do globo tem procurado interagir com essas temáticas.

\section{Referencial Teórico}

2.1 A relação entre Política Externa e a mídia: o jornalismo

O jornalismo surge como uma importante e poderosa ferramenta de comunicação no Estado Moderno, responsável pela divulgação da notícia, ou seja, aquilo que é de interesse público. Rossi (1980) classifica o jornalismo como uma fascinante batalha pela conquista das mentes e corações de seus alvos: leitores, telespectadores ou ouvintes. Na definição de Natalí (2004) jornalismo não é ciência, e por isso não existem critérios científicos para a definição do que venha a ser uma notícia que precisa ser publicada ou o que venha a ser uma notícia que não fará falta no noticiário em caso de nãopublicação. No entanto é importante salientar que a notícia além de ser a matéria-prima do jornalismo, pode ser considerada um importante instrumento para a formação da opinião pública.

$\mathrm{Na}$ Era da Informação, as empresas jornalísticas e outros veículos de comunicação como a indústria cinematográfica passam a ganhar mais importância no jogo político internacional, uma vez que a visibilidade proporcionada pela produção de imagens e percepções positivas dos Estados junto a formação da opinião pública, remetem a atenção das instituições governamentais a construírem imagens positivas às suas reputações, tanto no âmbito interno, como externo, para alcançar os fins políticos, como destacam Nogueira e Burity (2014).

O advento das Novas Tecnologias de Informação e Comunicação tem trazido a possibilidade de integrar diferentes sociedades e indivíduos de todo o mundo a interagir entre si em um processo global diferente das mídias tradicionais do ambiente corporativo e estatal (Aguiar, 2008). O autor afirma ainda que a sociedade vive conectada em rede, ou seja, há um sistema de canais de comunicação com diversos atores sociais que anteriormente só eram alcançáveis por filtros e intermediações (técnicas, profissionais ou políticas), geralmente das empresas de comunicação e órgãos estatais responsáveis justamente por selecionar e redistribuir informações, como as agências de notícias e os veículos de mídia. A nova realidade tornou com que as informações fossem disseminadas sem limites de tamanho, profundidade ou capacidade de armazenamento de informações, desencadeando em uma rede.

Ao mesmo tempo em que se desenvolvem essas novas tecnologias, há um aumento gradativo em escala exponencial referente a acessibilidade das fontes, personagens e interpretações da informação veiculada, alguns dos elementos fundamentais para a composição no trabalho do jornalista. 
O profissional do jornalismo é pautado pela narrativa dos fatos de forma isenta e imparcial, pois o jornalismo surgiu com a noção de uma mídia interlocutora e independente nos anos 70 por apresentar atração do domínio dos meios estatais nos veículos de comunicação em vigor naquela época, como destaca Burity (2013)

\begin{abstract}
Essa mudança de percepção sobre a forma de produzir informação marcaria de forma clara uma quebra da influência dos veículos estatais sobre a opinião de suas populações, tornando-os pouco influentes e com efeitos de "produção de realidade" mais limitados do que os veículos privados (...). A independência jornalística e a informação democrática com objetivo de formar a opinião dos cidadãos, apesar de ter evoluído bastante em relação à imprensa estatal manipuladora dos governos totalitários, ainda está longe de ser verdade. (BURITY, 2013, p.171)
\end{abstract}

Neste contexto, Nogueira e Burity (2014) evidenciam que o discurso se torna um instrumento de disseminação de ideias políticas, bem como a sua ampliação e divulgação sendo realizada pelos meios de fusão internacional das empresas de comunicação. Desta forma grandes fusões de empresas e a formação de conglomerados de comunicação tem ocorrido nos últimos 40 anos em várias partes do mundo, o que comprova a ideia de aldeia global citada por Santos (2008) e defendida por Marshall McLuhan que consiste na teoria de que os seres humanos estão interconectados por meio do fluxo de informações formando teias, e esse conjunto de teias leva ao surgimento de aldeias globais.

Nesse mesmo sentido, Carvalho (2015) observa que na sociedade em rede, a informação se torna uma espécie de insumo e também é o produto do processo produtivo, uma vez que o recente paradigma tecnológico, na nova ordem econômica, se organiza em função das novas tecnologias de informação e comunicação.

Moreira (2017) defende que a essa ideia de modernidade perpassada pela Era da Informação está articulada com a aceleração do tempo e por sua vez também é associada à urgência pela informação. Portanto, o aumento do capital financeiro, a facilidade de acesso à informação e a ascensão social tem despertado a exigência da sociedade pelo consumo imediato. A globalização explora elementos das relações internacionais para propagar as suas ideologias, principalmente no capitalismo, empregando as intensas movimentações econômicas. Desta forma o ambiente internacional é exposto as mudanças que ultrapassam as fronteiras dos Estados e resultam dos interesses das diversas potências (Costa, 2011). Logo, Burity (2013) afirma que há um relacionamento entre as empresas de comunicação privada e os governos dos Estados que interagem de forma complexa ao disseminar a informação no sentido de cumprir os objetivos traçados nas Políticas Externas. Esses atores não enfraquecem ou perdem a soberania, mas acabam se adaptando aos novos meios de comunicação para atingir os objetivos e interesses preestabelecidos. As relações governo-mídia se fortalecem quando - Estado se torna o fornecedor de matéria-prima para esses veículos disponibilizando informações oficiais ou de interesse do governo para pautar as suas Redações. Com isso é possível constatar que apesar dos conglomerados terem características globais, as notícias veiculadas atendem aos interesses domésticos. 
Os meios de comunicação de massa - com a sua capacidade de construir e de disseminar informações e realidades sociais por meio de seu discurso diário em larga escala - compartilham com outros agentes a função de constituir a definição de regras, identidades e interesses, de modo que, em um movimento dialógico, são, igualmente, influenciados pela realidade política internacional. (NOGUEIRA; BURITY,2014, p.376)

Com o aumento do fluxo de informações, o desenvolvimento das tecnologias da informação e comunicação que tem reduzido a dimensão das fronteiras entre os Estados e aproximando populações heterogêneas. Carvalho (2015) aponta para esse aspecto ao relatar que os avanços impulsionados pela globalização e pela evolução das novas Tecnologias da Informação e Comunicação interferem no panorama das Relações Internacionais e nas relações diplomáticas entre os países na sociedade contemporânea e com isso as práticas diplomáticas tradicionais vigentes começam a ceder espaço para uma revolução que atenderia de forma eficaz as necessidades, entre elas, as disputas de poder e a correlação e forças entre países que lideram os blocos hegemônicos.

O jornalismo internacional tem ganho cada vez mais notoriedade por conta dos efeitos que a informação estrangeira pode ocasionar dentro do sistema financeiro de um Estado, interferir nas relações políticas de diversos países e afetar até mesmo nas relações diplomáticas, a forma como a notícia se dissemina e a velocidade que a mensagem chega ao receptor na Era da Informação potencializa o poder de nações que utilizam os meios midiáticos para propagar suas ideologias.

\subsection{0 jornalismo e a cobertura internacional}

Com o estreitamento das relações entre os povos por meio das novas tecnologias da informação e comunicação e o crescimento das atenções voltadas ao noticiário estrangeiro, é importante compreender o significado do jornalismo internacional na sociedade contemporânea. Moreira (2017), considera o jornalismo internacional como o exercício de cobrir fatos que não estão ocorrendo no território do país no qual o impresso é produzido, ou a produção de notícias ligadas ao estrangeiro. Bonfim e Muller (2016) classifica o jornalismo internacional como uma instância de poder simbólico, do qual a informação manipulada recebe um significado que será transmitido com viés ideológico. Ao mesmo tempo os autores alertam para a possibilidade em haver desinformação, uma vez que esse processo de retirar uma informação dentro de um contexto de origem, sendo transportada para outro pode modificar o sentido da mensagem.

$\mathrm{Na}$ concepção de Aguiar (2008), o Jornalismo Internacional conta com a particularidade de variar o objeto de interesse de acordo com a procedência nacional do profissional que apura e com a localização - seja ela física ou geográfica - do veículo ao qual a reportagem se destina. Além do mais o que for exterior para uns não o será para outros; e o assunto que é "doméstico" para um país é "internacional" para todos os demais. Desta maneira, Bonfim e Muller (2016) concluem que a mediação no jornalismo internacional se desenvolve em um contínuo contato entre a realidade construída pelas notícias e as concepções sobre as "esferas da realidade" exteriores. Nessa mesma linha de raciocínio Aguiar (2008) avalia que as características narrativas do jornalismo fornecem 0 capital simbólico às empresas jornalísticas 
internacionais, visto que elas não criam a maior parte dos temas aos quais se dedicam e isso ocorre porque muitos veículos buscam as informações através das agências de notícias especializadas.

\begin{abstract}
As agências - empresas criadas originalmente com o objetivo de economizar custos para jornais e revistas associados em coberturas de guerra ou no exterior - cresceram a ponto de dominar entre 66 por cento e 90 por cento do conteúdo publicado no noticiário internacional do Terceiro Mundo, dependendo da medição e da metodologia empregada. Dentro da lógica do capital pós-industrial, baseado na troca de serviços e bens intangíveis (como a informação), o downsizing das empresas jornalísticas reflete-se na redução de pessoal, a começar pelos mais custosos ao orçamento - entre eles, correspondentes. (AGUIAR, 2008, p.11)
\end{abstract}

Portanto é notória a influência exercida pelas agências de notícias internacionais nos principais veículos de informação em diversos países, pois, "as empresas dependem do material disponibilizado pelas agências de notícias, o que incorre em características como a homogeneidade do noticiário internacional e cristalização de discursos e representações sobre países, povos e culturas" (BONFIM; MULLHER, 2016 p.65). Neste contexto, Burity (2013) complementa que há cinco formas diferentes de atuação das relações internacionais intrinsicamente ligados à mídia em situações que vão depender dos atributos, os tipos de atividades, os contextos e os conceitos no ambiente da Política Externa a ser implementada.

A autora classifica as atuações da mídia como controladora que decorre quando os veículos de comunicação se tornam influentes na formulação de políticas relacionadas às crises humanitárias; constrangedora quando procuram influenciar os líderes políticos a tomar determinadas decisões e agir dentro de um prazo estabelecido; também podem ser interventoras quando existe uma atuação na forma de mediadora das negociações estrangeiras; instrumentais quando se torna uma ferramenta para mobilizar suporte ao selar acordos; e ainda conflituosas quando a mídia exerce a função de agente de disseminação de notícias causadoras de conflitos.

Somado a isso, Carvalho (2015) recorre a Gramsci ao se referir sobre a corrida pela hegemonia, a partir do momento em que a conduta de países hegemônicos detentores de poder político e econômico, como os Estados Unidos, ao buscar o controle estratégico da informação, no ciberespaço ou em circuitos restritos de órgãos de governos e centros de poder, se lança na disputa pelo controle das regras do jogo para manter a sua condição hegemônica de liderança no cenário internacional fazendo valer seus valores, a sua vontade política e os seus interesses econômicos.

Contextualizando o exposto, Camargo (2013) cita Semeraro para explicar como se caracteriza a manifestação hegemônica. Para a autora a hegemonia ocorre quando os interesses específicos do grupo hegemônico são compartilhados pelos demais grupos sociais. O compartilhamento de interesses se manifesta de duas formas, a primeira se expressa de modo dirigente em relação aos grupos sociais aliados, e a segunda de modo dominante, em relação aos grupos adversários e subalternos.

A mídia acaba fazendo parte do jogo de dominação exercido pelas potências hegemônicas. Ainda conforme o estudo de Gramsci citado por Carvalho (2015), o exercício da hegemonia tem como característica a 
dominação de uma determinada classe social sobre a outra, evidenciando a supremacia de um Estado dominante no sistema internacional. Esse fenômeno combina a coerção ao consentimento de determinados grupos sociais detentores do poder estatal.

O que ocorre em algumas ocasiões é a manifestação desse poder através do convencimento, preterido à coerção. Neste sentido Khumthukthit (2010) e Pecequilo (2017) recorrem à Nye, importante estudioso do campo das relações internacionais e redator da obra "power and interdependence".

\begin{abstract}
Ao contrário do hard power que envolve a ordenar ou forçar os outros, o soft power é a capacidade de cooptar ou persuadir os outros países ou atores a acompanhar ou a querer o que o país de origem quer. Nas palavras de Nye, "soft power", ou a habilidade de atrair, emana de três recursos: a sua cultura (em locais onde é atraente para os outros), seus valores políticos (quando eles são aceitáveis tanto no doméstico como no exterior), e sua política externa (quando é vista como legítima e tem autoridade moral). (KHUMTHUKTHIT, 2010, p.19-20)
\end{abstract}

Ao empregar essa técnica de manifestação de poder, utilizando a imposição da sua cultura, valores e instituições de forma branda, sutil e cooptativa, o Estado obtém admiração, prestígio e respeito dos demais que compõem o sistema internacional. Diante desse processo, Costa (2011) afirma que na sociedade contemporânea deixamos de nos tornar Homos Sapiens para nos tornar Homo digitalis porque as nuanças da globalização tem levado a um processo tecnológico que viabiliza as informações e se tornam acessíveis no âmbito mundial. Com os cenários cada vez mais heterogêneos, constitui no tabuleiro internacional alianças que cunham o interesse pelo poder através de tendências descentralizadoras, como ocorre no mercado financeiro, onde alguns Estados adotam medidas de barganha para fomentar as exportações ou as importações, movimentando o comércio exterior a ponto de modelar a atuação no cenário internacional.

No entanto, Sato (2003) chama atenção para o fato de o Estado Moderno deter a soberania que é um dos princípios fundantes e o estabelecimento de uma ordem capaz de acomodar esse princípio com as noções de justiça e equidade, algo que tem se tornado desafiante para os estadistas. Além do mais, a autora ressalta que a retórica da globalização se manifesta cada vez mais evidente nos sinais das diferenças culturais e religiosas entre os povos, pois essas diferenças revelam um paradoxo da própria existência humana e são essenciais para a preservação da multiplicidade e riqueza desse fenômeno que dificulta a compreensão mútua e a convivência. Sato (2003) também destaca que cada ator tende a avaliar de forma diferente o significado de uma disputa seja ela comercial ou territorial, optando pela cooperação ou pelo conflito armado.

Contudo, Bonfim e Muller (2016) endossa que o uso do jornalismo internacional prevalece as ações publicitárias no sentido de os Estados conseguirem a efetivação de seus interesses, sendo eles "indiretos" para a construção de uma imagem positiva perante os demais atores da ordem internacional ou diretos quando os objetivos se referem às influências na resolução dos conflitos. A utilização da mídia informativa privada global exige um plano de comunicação que envolva o uso dos discursos publicitários de forma "disfarçada" na imprensa e o jornalismo pelas suas características 
textuais pode assegurar legitimidade nesse processo. É neste sentido que emerge o significado e a importância da utilização da diplomacia midiática empregada na Política Externa, principalmente dos países hegemônicos como maneira de impor sua cultura e valores ao país dominado, vestindo farda do imperialismo de forma legitimada e reformada por diversas potências mundiais, conforme Costa (2011).

Bonfim e Muller (2016) completam ao afirmar que a diplomacia midiática parte do interesse dos formuladores de política externa em compreender ou utilizar o impacto das notícias de alcance global. A informação jornalística é sustentada pela credibilidade que o jornalismo possui ao corpo social ao invés da publicidade.

\section{Os países buscam presença positiva nos materiais jornalísticos de empresas privadas que, por serem encarados como "informação independente", seriam mais confiáveis aos olhos do público. Mesmo a concepção de "objetivos diretos" na utilização da mídia informativa para a resolução de questões diplomáticas evidencia a percepção da força do poder simbólico das notícias. (BONFIM;MULLER, 2016, p.76)}

E por fim, Moreira (2017) conclui que o jornalismo internacional é uma especialização ou área do jornal, ou da prática do jornalista, e não um gênero porque o gênero está ligado ao estilo narrativo, como nota e artigo, ou seja, se limita ao formato textual. Portanto, o termo gênero jornalístico não cabe para se referir ao jornalismo internacional que é compreendido como um ramo ou especialização que pode ser o foco de uma mídia ou o conjunto com outras que venham a se constituir.

\subsection{Diplomacia midiática}

Partindo da premissa do surgimento, fortalecimento e consolidação das mídias de comunicação em massa, é nítido observar que o jogo diplomático tem sofrido modificações e a temática necessita de investigação aprofundada a respeito da interação entre a mídia, jornalismo e as relações com os estudos referentes a Política Externa.

Em 1987, o professor de Ciências Políticas da Universidade de Harvard, nos Estados Unidos, Eytan Gilboa (1987), criou o termo diplomacia midiática que na concepção do intelectual se trata de um assunto multidisciplinar, pois envolve conhecimentos nas áreas das Relações Internacionais, Comunicação e Ciências Políticas.

Uma das pesquisadoras brasileiras que se debruçou sobre o assunto é Burity (2013) que define a diplomacia midiática como um instrumento de análise aos estudos relacionados sobre os efeitos dos veículos de difusão coletiva e as pesquisas de recepção, análise de discurso e opinião pública. Para a escritora, a diplomacia pública estaria associada a formação da imagem e da propaganda política e diplomacia na mídia há a utilização dos meios de comunicação que estabelece as pontes entre os Estados e os atores não estatais para barganhar a confiança e avançar nas negociações, obtendo 0 apoio público para os acordos. "A diplomacia feita pela mídia é o modelo que compreende os meios de comunicação com ator das relações internacionais, enxergando os meios de comunicação e os jornalistas como o quarto poder, atuando nas negociações internacionais" (BURITY, 2013, p.176) 
A conquista dos objetivos ocorre quando os veículos de comunicação ou as agências de notícias realizam a cobertura de conferências, entrevistas oficiais e visitas de chefes de Estado a um determinado país e há a consecução dos interesses estatais, sempre explorando a mídia como elemento essencial e estratégico na condução da política externa. O poder é legitimado com a associação da imagem ao líder e o papel assumido no cenário internacional

Em outro trabalho desenvolvido por Burity com Nogueira (2014), as autoras definem a diplomacia midiática como um campo que analisa os efeitos dos modernos meios de comunicação e da imprensa sobre os assuntos de Estados em política externa e trata também da interferência desses novos meios de comunicação nos assuntos que envolvem a agenda internacional e a disputa pelo poder, seja ele político, bélico ou econômico. Em consenso, as pesquisadoras reforçam a confusão que há entre diplomacia pública e a midiática pela forma de atuação serem similares, onde na primeira o elemento principal é a propaganda e na segunda o meio de comunicação é utilizado como ferramenta de negociação e mobilização do público para obter o apoio necessário para que os acordos sejam firmados. Tal análise é reforçada por Carvalho (2015).

\begin{abstract}
A diplomacia passou a adquirir características de uma instituição resistente e adaptável, onde a comunicação passou a ser cada vez mais essencial como aspecto estratégico na condução da política externa. O poder, por exemplo, ficou mais associado à imagem do líder da nação e seu papel assumido perante a comunidade internacional, e não apenas relacionado ao seu poderio bélico e político" (CARVALHO, 2015, p. 69-70)
\end{abstract}

A disputa pelo poder tem deixado os meios tradicionais e se estendido à mídia com a revolução tecnológica que atinge também os meios de comunicação. Diante desse cenário, as Nações hegemônicas recorrem a prática da diplomacia midiática, no sentido de impor seus valores, ideologias e cultura nos Estados dominados, aqui se manifestando o Soft Power, conceito de Nye sobre o exercício do poder brando, como já mencionado anteriormente. Os principais líderes buscam inserir nos noticiários assuntos ligados aos temas da agenda internacional com a perspectiva que atendam os próprios interesses e propagando a ideologia defendida por essa hegemonia.

\title{
2.4 Temas da Agenda Internacional
}

Os temas da agenda internacional emergem a partir da necessidade que a sociedade contemporânea busca para solucionar conflitos, compreender fenômenos sociais, políticos, estratégicos, econômicos e culturais. Pecequilo (2017) ressalta aqui, mais uma vez, Nye e Kehoane para explicar essa forma de interação que o sistema internacional atravessa ao ser caracterizado com uma mistura de eventos estatais e não estatais de onde emergem os fenômenos da interdependência e da transnacionalização.

Enquanto a primeira refere-se ao maior estreitamento dos laços entre atores e a criação de dependências mútuas entre eles - que passam a ser afetados diretamente uns pelos outros -, a segunda relaciona-se à fragilidade das fronteiras dos Estados, isto é, ao fato de que as questões internacionais não se limitarem mais ao território, mas envolverem fluxos globais de transportes, pessoas, tecnologia e transações de qualquer natureza, não apenas econômica. (PECEQUILO, 2017, p.25) 
Ainda conforme a autora, as tradicionais maneiras de pensar e fazer política sustentadas no conflito e nas fronteiras foram se tornando mais flexíveis ainda durante o mundo bipolar, quando havia duas superpotências: de um lado capitalista liderado pelos Estados Unidos e do outro o socialismo liderado pela União Soviética. Conclui-se que as formas de negociação e convivência entre diversos povos foram gradualmente se modificando, buscando inserir nas pautas das conferências e encontros internacionais temas econômicos, sociais e relativos aos bens comuns e é a partir daí que se cria a idéia de existência da agenda internacional. Essa relação perdura até os dias atuais com 0 advento da Nova Ordem Mundial, onde o mundo está multipolarizado, mesmo com o predomínio dos Estados Unidos como líder do sistema internacional.

Viana (2017) aponta que os temas da agenda internacional podem ser classificados conforme os assuntos que envolvem: a segurança, o desenvolvimento, a cooperação econômica, técnica e científica, o meio ambiente e os recursos naturais, a fome e a segurança alimentar. Outro ponto que merece destaque são as relações cooperativas entre os Estados e atores não-estatais, e essas interações provocam o multilateralismo, onde a estrutura do sistema internacional seria alterada por formas de cooperação e governança. O fenômeno da globalização e a regionalização seria a base da cooperação e interdependência entre as sociedades, aliando um ao outro seria possível chegar a um grau de dominação quando ultrapassasse as fronteiras transnacionais. "A globalização, como o próprio nome diz, apresenta escala mundial e tem como premissa a criação de um mundo único, sem fronteiras, por meio da aceleração do contato entre os Estados e o aprofundamento dos seus laços de cooperação" (Pecequilo, 2017, p.29).

Como foi exposto, o desenvolvimento das tecnologias da informação e comunicação tem derrubado as barreiras entre os países, aproximando os povos e influenciando culturas. A diplomacia midiática também pode atuar na interferência dos assuntos externos que predominam na agenda internacional e na política exterior dos Estados

Se um Estado tem uma forte máquina midiática, ele tem um forte agenda setting -hipótese segundo a qual a mídia, pela seleção, disposição e incidência de suas notícias, vem determinar os temas sobre os quais o público falará e discutirá - e também capacidade de incluir um tema de seu interesse na pauta da mídia internacional e de outro Estado alvo, ainda mais se tiver a capacidade de fazer com que esse tema atinja prioridade dentro dos temas veiculados na mídia daquele país. (BURITY, 2013, p.172)

Ainda, Pecequilo (2017) sustenta que o Brasil adota dois pilares na sua política externa: um é representativo dos princípios e valores do seu povo e o outro se relaciona à inserção de assuntos específicos na agenda. Relacionando a política externa, diplomacia midiática e a própria desenvoltura do jornalismo, é possível investigar como a grande mídia impressa do Brasil tem trabalhado com as notícias internacionais. E neste caso foi selecionado pelo autor da pesquisa as revistas Época e Veja, por serem dois periódicos com elevada tiragem e circulação nacional. 
a. Veja x Época - A cobertura internacional

No levantamento feito pela Associação Brasileira de Editoras de Revistas, a Veja e a Época são os periódicos que detém a maior circulação nacional. De janeiro até setembro de 2014, a revista Veja, que pertence ao Grupo Abril, registrou uma média de circulação de 1.167.928 exemplares. Enquanto que, nesse mesmo período, a revista Época - integrada ao Grupo Globo - apresentou uma circulação média de 390.709 exemplares. Os dados demonstram a força e o poder que os dois grupos de comunicação tem perante a formação da opinião pública. (ASSOCIAÇÃO BRASILEIRA de EDITORAS DE REVISTAS, disponível em 2015. < http://www.aner.org.br/dados-demercado/circulacao >. Acesso em 06 de julho de 2018).

A pesquisa analisou 13 revistas Veja no período de janeiro até março de 2018, o que representa um trimestre do ano em um universo de 1.282 páginas. Foram analisadas, principalmente, as informações das seções internacionais, mas também as notícias do exterior que faziam contextualizações ao meio ambiente, economia, saúde e religião por afetar diretamente as relações internacionais.

Para facilitar a compreensão, definindo o foco do objeto de estudo, foram desprezadas as informações de cunho internacional alusivas ao esporte (a não ser que tenha relação com a política), cultura (no que diz respeito as tendências musicais, lançamentos de filmes e exposições artísticas) e inovações tecnológicas, pois o autor da pesquisa entende que apesar de afetar o ambiente social, são informações contidas em temáticas muito específicas e ficaria dispersa a investigação. Desta mesma forma os boletins contidos nas revistas - aquelas informações superficiais com pouco conteúdo e leitura rápida - também foram desconsideradas.

O autor da pesquisa empregará o termo contexto em algumas ocasiões para evitar o uso da palavra reportagem, pois em algumas publicações mais de um Estado se tornou elemento central ou periférico nas matérias jornalísticas, assim como em alguns casos a reportagem produzida abordou não apenas um tema da agenda internacional, como dois ou mais assuntos - uma hora falando de meio ambiente e outra relacionando com a segurança internacional, por exemplo. Constata que os assuntos e os atores das informações, muitas vezes estão relacionados entre si.

De janeiro até março de 2018, a revista Veja lançou ao leitor 65 publicações internacionais, algumas envolviam o Brasil em um determinado contexto. Foram 7.806 linhas formadas ora por duas, ora por três colunas, distribuídas pelas 161 páginas dedicadas ao conteúdo internacional e com inserção de 128 fotografias de vários tamanhos. O jornalista Duda Teixeira teve o nome assinado em 16 publicações e seguido por Diogo Schelp com 15 ambos da seção internacional. Marcelo Sakate foi o jornalista com o nome assinado mais vezes nas publicações estrangeiras encontradas fora da seção internacional, ele foi mencionado em cinco ocasiões, todas elas na seção de Economia.

Dos conteúdos analisados, os Estados Unidos serviram de elemento, seja como protagonista ou coadjuvante nas publicações - 32 vezes, seguido pelo Brasil inserido em 8 contextualizações, ficando a China em terceiro entrando em 6 contextos, a Síria com cinco destaques e ainda a Rússia, Venezuela e Itália em 4 aparecimentos cada. 
Para facilitar a organização dos dados e tornar a compreensão mais didática, o autor da pesquisa divide os temas da seguinte forma: Política informações relacionadas ao ambiente político interno e/ou externo de uma determinada Nação, eleições em um país ou atentado a democracia. Segurança - quando as reportagens abordam questões referentes às guerras, tensões diplomáticas, homicídios ou outros crimes comuns dentro de determinado Estado. Saúde - decorre quando o conteúdo internacional aborda uma informação que pode afetar a saúde pública global, como é o caso da epidemia de sarampoo. Direitos Humanos - são reportagens que denunciam alguma prática que atenta contra os Direitos Humanos como as questões dos refugiados, as imigrações e holocausto. Religião - assuntos que envolvem o clero e que de alguma forma afeta a política dos Estados e a influência social. Cooperação, Economia e Desenvolvimento - matérias alusivas as medidas que visam proteger o comércio de determinada região, ou ações de cooperação de investimento de um país em outro, políticas fiscais adotadas em determinada economia, entre outros dessa natureza. Meio Ambiente - informações que afetam o ecossistema de determinada região do globo e pode afetar Nações vizinhas ou países mais distantes.

A pesquisa constatou que nas reportagens da Veja, o tema Segurança apareceu em 26 contextos, seguido por Política com 22 contextualizações. A temática Cooperação, Economia e Desenvolvimento ficou em terceiro com 12 contextos, Meio Ambiente (10), Direitos Humanos (7) e Religião completando o quadro.

No que se refere a segunda revista de maior circulação nacional, a Época, foram investigadas 13 edições do período de abril até junho de 2018. Das 1122 páginas editadas do periódico, 177 páginas foram dedicadas aos assuntos internacionais, foram 9109 linhas variando de duas à uma coluna distribuídas por 64 publicações entre crônicas, reportagens e artigos alusivos aos assuntos internacionais que em algumas ocasiões traziam também o Brasil para algumas análises ou comparações. Ao longo dessas edições foram publicadas 119 fotografias com variados tamanhos, apesar de o número de fotografias inseridas na Época ser menor em quantidade que a Veja, notou-se maior exploração desse recurso no que diz respeito a ocupação de espaço na página, pois verificou-se que em alguns momentos as fotos chegavam a estampar uma e até duas páginas inteiras fazendo fundo aos textos.

Observou-se também que a revista explora menos ilustrações, gráficos e boxes do que a Veja. Outro comparativo se refere as seções de publicação, na revista Veja é mais fácil buscar as notícias internacionais por estarem - na maioria das vezes - divididas nas seções de Internacional, Economia e Meio Ambiente. Enquanto que na revista Época, foi necessário realizar praticamente a leitura toda do conteúdo para fazer o recorte das notícias internacionais, uma vez que há uma certa ausência de divisão desses conteúdos por Seções.

O autor da pesquisa procurou utilizar os mesmos critérios na coleta de dados da Época quando investigou a Veja, ou seja, excluindo as publicações direcionadas a culinária, cultura - no sentido de enfocar publicações de livros, lançamentos de músicas, CDs ou DVDs, estreias de filmes estrangeiros - e esportes (a não ser que tenha algum vínculo com a política internacional como é o caso da matéria que tratou sobre os atuais presidentes da Argentina, Uruguai e Paraguai terem um passado na cartolagem, o uso da Copa do Mundo de 1934 por Mussolini para propagação dos ideais fascistas e o conflito 
armado entre El Salvador e Honduras que intensificou as tensões entre os dois Estados após partida de futebol entre as duas seleções.

Os Estados Unidos apareceram nas publicações em 28 contextos, seguido pelo Brasil com 16 menções - seguindo a mesma observação em Veja e presume-se pelo fato do periódico ser brasileiro, mesmo sendo investigadas as informações internacionais, notou-se em vários momentos a inserção do Brasil como exemplo no cenário político ou econômico para efeitos comparativos. Destaque também para a Argentina com 11 contextos e Rússia com 10 menções. Enquanto que a Veja traçou panorama de 34 localidades, a Época se mostrou nesse sentido mais "internacional" ao contextualizar 70 Estados (entre denominações gerais como Oriente Médio, Europa, Reino Unido e o mundo em geral). $O$ autor da pesquisa também notou o grande espaço dado ao periódico para os assuntos que envolvem os países subdesenvolvidos.

Apesar de não ser o objeto de estudo da pesquisa, mas vale mencionar, os textos da revista Época se apresentam de forma mais literária e subjetivos, ou seja, muitas vezes contando fatos históricos ou focando em um ou mais personagens das matérias para chegar até o assunto central. Enquanto que os textos da revista Veja eram mais objetivos, trazendo apenas o fato em si e raramente faz leitura com os personagens para referenciar o assunto.

Outra dificuldade observada na revista Época é que em algumas publicações os assuntos centrais poderiam ser vários como é o caso de uma notícias que falou sobre o cenário político no Paraguai e na Venezuela às vésperas das eleições, as instabilidades das instituições democráticas nesses Estados, o histórico da Guerra do Paraguai e a falta de liberdade de expressão dos civis na Venezuela. Ao classificar o material nos assuntos foi levado em consideração a matéria em três aspectos: Democracia, Política Interna e Externa; Direitos Humanos e Segurança Interna e Externa. Outras publicações também se assemelharam com o que foi exposto e observado da mesma forma ao classificar. Assim como a notícia que observou o cenário político nas eleições americanas e traçou perfil de Donald Trump e Hilary Clinton sobre questões religiosas - neste caso foi levado em conta os aspectos Democracia, Política Interna e Externa; e Religião.

Desta forma, a Época surpreendeu o pesquisador ao trazer como uma das principais temáticas do periódico os Direitos Humanos - foram 24 menções relacionadas ao assunto e presume-se que tenha relação com a abertura maior às publicações dos países subdesenvolvidos, pois muitas reportagens mencionaram a fragilidade das instituições democráticas, falta de liberdade de expressão, racismo, movimentos feministas e imigrações nessas regiões.

No entanto, a análise do cenário político interno dos Estados, a preocupação com o futuro da democracia e as relações exteriores entre as Nações pautaram a maior parte da revista, elas entraram em 28 contextos. As questões que envolvem a segurança interna e externa dos Estados, como guerras, conflitos, violência e criminalidade receberam 21 menções. Vale destacar também a análise dos cenários econômicos, o desenvolvimento e a cooperação presentes na revista 14 vezes, seguido pelas causas de saúde, meio ambiente e religião uma única vez cada.

Constatou-se também que o maior colaborador da revista Época nesse período pesquisado foi o jornalista Ariel Palácios com 12 publicações, seguido pelos colunistas Helio Gurovitz (9), Mônica de Bolle (6) e Paulo Roberto Pires 
(5). Tanto, na Época como na Veja, os artigos que faziam relação com assuntos internacionais também foram observados. Esse tipo de texto se difere das reportagens pela semântica jornalística de cunho opinativo e na maioria das vezes é assinado por especialistas de uma área.

Desta forma é possível perceber a utilização das comunidades epistêmicas que podem ser compreendidas como um grupo de especialistas que influenciam a tomada de decisão dos Estados em temas centrais, ou seja, uma comunidade que pode influenciar no comprometimento de um Estado, além do mais as comunidades epistêmicas também se referem a uma rede de profissionais com experiência reconhecida e competências em um domínio particular, legitimando um conhecimento relevante naquele domínio ou área e as ações dos Estados ou de empresas na localidade dominada (CULPI apud HAAS, 2016).

As duas revistas trouxeram especialistas para tratar de diversos assuntos para garantir legitimidade ao conteúdo, como é o caso de economistas, ex-ministros e até embaixadores opinando sobre o cenário político, econômico e social em determinadas regiões.

Outra curiosidade é que a revista Época trouxe textos escritos por profissionais estrangeiros e traduzidos para o português. Foram quatro publicações, uma assinada por lan Lya e traduzida por Matheus Rocha, outra assinada por Laurent Telo traduzido por Dorothée de Bruchard. E ainda um texto de Karen Abbot e de André Tablet, ambos traduzidos por Mariana Nântua.

\section{Considerações finais}

Conclui-se a demonstração da importância econômica e política exercida pelos Estados Unidos, como ator principal das relações internacionais e detentor da hegemonia global, ocupando grande espaço dos noticiários internacionais da imprensa brasileira.

A relevância dada aos norte-americanos chega a tal ponto das revistas comentarem até mesmo o perfil do presidente dos Estados Unidos na sua intimidade como algumas reportagens que abordaram sobre o suposto romance com a atriz pornográfica Stephanie Clifford - mais conhecida como Stormy Daniels - ou a falta de interesse de Trump por livros.

De acordo com o professor Cláudio Fernandes (2018), o termo terrorismo, por exemplo, teria surgido no fim do século XIX, em algumas regiões da Europa com ação de indivíduos ligados a anarquia. Os métodos de guerrilha utilizados na Revolução Russa, em 1917 e durante a Guerra Fria pelos bolcheviques também foram classificado pelo Ocidente como terrorismo. Sabendo que durante a Guerra Fria, o principal rival dos Estados Unidos eram os soviéticos, o termo começou a se popularizar no Ocidente, a tal ponto que os inimigos dos norte americanos sejam classificados como terroristas, como ocorreu com o Iraque ao ser acusado no governo George W. Bush de enriquecimento de urânio para fabricação de armas nucleares - fato que depois da invasão dos americanos no Oriente Médio e a deposição de Saddam Hussein não foi comprovado. O mesmo ocorreu ao Taliban, grupo radical islâmico afegão com características de guerrilhas e que assumiu os ataques ao World Trade Center em setembro de 2001 - o grupo também foi considerado 
como terrorista pelos norte-americanos e essa ideia se disseminou nos países periféricos através da mídia.

$\mathrm{Na}$ atualidade, constatou-se nas reportagens analisadas que outros grupos como o Estado Islâmico, a Palestina - rival de Israel que recebe patrocínio e apoio tecnológico para segurança dos Estados Unidos e a Coréia do Norte, todos esses grupos radicais também são considerados inimigos dos Estados Unidos e em alguns casos são tratados como terroristas na imprensa brasileira, atenta-se para a falta de interpretação e divulgação da notícia pelos aspectos e pontos de vistas desses grupos. No entanto, o regime autoritário nessas localidades também inviabiliza a apuração jornalística para trazer o outro lado da reportagem.

Apesar de não ser o objeto de estudo da pesquisa, presume-se que venha desse contexto a ideia de que os inimigos dos norte-americanos sejam classificados como terroristas e o poder exercido pelo governo estadunidense, se aliando as agências de notícias internacionais e ocupando a maior parte dos espaços dos noticiários estrangeiros tenha colaborado para a disseminação das informações com a visão americanizada dos fatos. Diante disso, o autor desta pesquisa sugere a realização de outro estudo para o entendimento dessa manifestação.

A diplomacia midiática trata justamente sobre o uso dos meios de comunicação para divulgar as informações que convém a um determinado governo. Os Estados para legitimar suas ações utilizam a influência da opinião pública através do conteúdo jornalístico com a característica de um texto que transmita credibilidade na mensagem difundida e preterindo dessa forma 0 texto publicitário.

Partindo da premissa que os principais conglomerados de comunicação estão alinhados às nações poderosas e que exercem forte poder econômico nos veículos jornalísticos, essas Nações fortificam e consolidam a sua hegemonia exercendo o domínio de forma branda, evitando a utilização de ação coercitiva para impor sua cultura, assegurar o apoio das massas e manifestar sua influência nas sociedades periféricas.

Apesar de inúmeras publicações fazerem críticas a condução política de Donald Trump e seu perfil controverso, em muitas ocasiões os Estados Unidos são colocados como exemplo positivo em termos de medidas econômicas adotadas. Outro país que também recebeu menção positiva referente a economia foi a China. Em várias publicações, a Rússia e a Venezuela serviram de exemplo negativo em termos de autoritarismo de seus líderes e adoção de política econômica. Observou-se também grande preocupação com assuntos referentes a segurança, seja conflitos internacionais como violência urbana interna.

A cobertura internacional na imprensa brasileira foi alvo de críticas no artigo publicado por Saraiva (2000), após seminário proposto pelo Instituto Rio Branco que reuniu diplomatas e jornalistas acerca da análise de notícias e coberturas jornalísticas internacionais na mídia do Brasil. Saraiva (2000) constatou que a imprensa brasileira tem dado pouca importância às notícias do mundo e talvez tenha relação com o autoritarismo político vivido pelo Brasil durante o governo militar, agravado após sucessivas crises econômicas que limitaram a capacidade criativa da imprensa brasileira.

O autor do texto também critica a forma que os jornalistas brasileiros abordam essas noticiais pelo fato de serem baseadas em informações oficiais 
e não conseguirem cativar o público. A dificuldade de seleção de profissionais voltados para a área internacional e a retração financeira das Redações tem impactado na redução ou exclusão dos correspondentes no exterior - o que influi para a formação de um ângulo nacional na abordagem das notícias internacionais e reflete diretamente no maior consumo da informação vinda com o aspecto e olhar interpretativo das agências de notícias estrangeiras.

Diante das novas ferramentas tecnológicas, a informação tem disseminado mais rapidamente, atingindo em curto prazo vários atores no cenário mundial e isso tem se tornado desafiante para a imprensa

\section{Referências Bibliográficas}

AGUIAR, Pedro. Jornalismo internacional em redes. Rio de Janeiro: Cadernos da Comunicação, Série Estudos, Secretaria Especial de Comunicação Social, v.20, 2008.

ASSOCIAÇÂO BRASILEIRA DE EDITORAS DE REVISTAS, 2014. Disponível em: < http://www.aner.org.br/dados-de-mercado/circulacao >. Acesso em 06 jul. 2018.

BOMFIM, Ivan Elizeu; Muller, Karla Maria. Diplomacia midiática e jornalismo internacional: as notícias globais no âmbito da política externa. Rev. FSA. Teresina, v.13, n.5, art.4, p.61-79, set./out. 2016.

BURITY, Caroline Rangel Travassos. A influência das mídias nas relações internacionais: um estudo teórico a partir do conceito de diplomacia midiática. Geografias da Comunicação, João Pessoa: Contemporânea, v.1, n.21, a.11, 2013.

CAMARGO, Adriane de Sousa. Globalização e hegemonia nas relações internacionais: o caso da Via Campesina por uma perspectiva gramsciana. Dissertação (Mestrado em Relações Internacionais da Universidade de São Paulo), São Paulo, 2013.

CARVALHO, Yasmin Coelho Santos. A diplomacia midiática na sociedade em rede: uma análise sobre o caso Snowden. Ilhéus: C@LEA - Cadernos de Aula do LEA, n.4, p.61-79, nov. 2015.

COSTA, William. As relações internacionais frente a globalização. Revista Idea. Uberlândia, v.2, n.2, p.1-15, jan./jul. 2011.

CULPI, Ludmila Andrzejewski. Empresas Transnacionais: uma visão internacionalista. Curitiba: Intersaberes, 2016.

FERNANDES, Cláudio. Terrorismo. Disponível em: < https://historiadomundo.uol.com.br/idade-contemporanea/terrorismo.htm > Acesso em 22 jul. 2018.

GILBOA, Eytan. American Public opinion toward Israel and Arabic-Israeli conflict. Lexington: Lexington Books, 1987

HAAS, Peter M. Introduction: Espistemic Communities and International Policy Coordination. International Organization, v.46, n.1, p.1-35, 1992.

KEOHANE, Robert; NYE, Joseph. Power and Interdependence. New York: Harper Collins, 1989.

KHUMTHUKTHIT, Ploy. A nova diplomacia pública do Japão. Dissertação (Mestrado em Relações Internacionais da Pontifica Universidade Católica do Rio de Janeiro), Rio de Janeiro, mai. 2010.

MATTELART, Armand. Multinacionais e sistemas de comunicação: os aparelhos ideológicos do imperialismo. São Paulo, Ciências Humanas, s.d. 
História da sociedade da informação. São Paulo: Loyola,

2002

MCLUHAN, Marshall. Os meios de comunicação como extensões do homem. 5 ed. São Paulo: Cultrix, 1979.

. Os meios de comunicação como extensões do homem. 5ed.

São Paulo: Cultrix, 1979.

MATTELART, Armand. Multinacionais e sistemas de comunicação: os aparelhos ideológicos do imperialismo. São Paulo, Ciências Humanas, s.d. . História da sociedade da informação. São Paulo: Loyola, 2002

MCLUHAN, Marshall. Os meios de comunicação como extensões do homem. 5 ed. São Paulo: Cultrix, 1979.

. Os meios de comunicação como extensões do homem. 5ed.

São Paulo: Cultrix, 1979.

NATALÍ, João Batista. Jornalismo Internacional. São Paulo, Contexto, 2004

NOGUEIRA, Silvia Garcia; BURITY, Caroline. A construção da imagem do Brasil no exterior e a diplomacia midiática no governo Lula. Revista de Ciências Sociais, João Pessoa, n.41, p. 375-397, out. 2014.

NYE, Joseph. Cooperação e conflito nas relações internacionais: uma leitura essencial para entender as principais questões da política mundial. Trad. Henrique Amat Rego Monteiro. São Paulo: Gente, 2009.

PECEQUILO, Cristina Soreanu. Temas da agenda internacional: O Brasil e o mundo. Curitiba: Intersaberes, 2017.

SANTOS, Roberto Elísio dos. As teorias da comunicação: da fala à internet. São Paulo: Paulinas, 2ed, 2008.

SARAIVA, José Flávio Sombra. A Construção da notícia internacional na imprensa brasileira. 2000 Disponível em: < http://www.scielo.br/pdf/rbpi/v43n1/v43n1a12.pdf >. Acesso em: 21 jul. 2018 SATO, EIITI. Conflito e cooperação nas relações internacionais: as organizações internacionais no século XXI. Rev. Bras. Polit. Int. Brasília, v.46, p. 161-176, 2003.

VALENTE, Leonardo. Política Externa na Era da Informação. Rio de Janeiro: Revan, 2007.

VIANA, Caroline Cordeiro. Rota de Aprendizagem da Uninter - aulas 1-6. Temas da Agenda Internacional. Curitiba, 2017. 


\section{Apêndice}

1. Publicações observadas nas revistas Veja

1.1. Edição de 3 de janeiro de 2018

Que boas-festas, que nada!

Os muros de Donald Trump

Impulsos para novos vôos

De costas para a Cúria

A fantasia no poder

A ditadura se protege

Um acerto moral

1.2. Edição de 10 de janeiro de 2018

Repúdio a todos

O tamanho do botão

Os gigolôs da paz

1.3 Edição de 17 de janeiro de 2018

Em busca da verdade

Imagem da Semana

A ameaça das fake news

O circo está armado

Um intruso na Casa

$\mathrm{O}$ que eles tem em comum com Trump

1.4. Edição de 24 de janeiro de 2018

Eles não acham o Papa pop

1.5. Edição de 31 de janeiro de 2018

No piloto automático

O conflito entra em outra fase

Ponto fora da curva

Os donos do mundo

1.6. Edição de 7 de fevereiro de 2018

A coroação de Putin

Estado da desunião

Que história é essa?

A China descobre o Brasil

Para o alto e avante

1.7. Edição de 14 de fevereiro de 2018

Um Lênin diferente

Dança da coalizão

Diplomacia olímpica

Segunda-Feira de cinzas

1.8. Edição de 21 de fevereiro de 2018 Um teste de hospitalidade 
Um povo que acolhe e rejeita

Era uma vez Zuma

Os presentes de Bibi

Sem refúgio

O porre de Trump

As mãos da limpeza

1.9. Edição de 28 de fevereiro de 2018 Imagem da Semana

$O$ avanço dos fascistas

Ele serve até fake news

O futuro dos venezuelanos

Guerra dos Canudos

1.10. Edição de 7 de março de 2018

Imagem da Semana

$X i$ veio para ficar

$\mathrm{O}$ que quer Xi Jiping

Apego às armas

Um susto vergonhoso

1.11. Edição de 14 de março de 2018

Imagem da Semana

A chantagem de Kim

Já está combinado

A guerra no Jardim do Éden

O populismo vence

Muita faísca, pouca luz

1.12. Edição de 21 de março de 2018

O chefe tirano e Rex

$O$ veneno de Putin

Economia da violência

Sinal Vermelho

O planeta água pede socorro

O paradoxo dos rios e lagos

As guerras do futuro próximo

Cobrar para não faltar

Os oceanos estão à deriva

1.13. Edição de 28 de março de 2018 Imagem da Semana

Um fim amargo

Da pirataria à inovação

2. Publicações observadas nas revistas Época

2.1. Edição de 2 de abril de 2018

As campanhas digitais vieram para ficar

Game of Thrones andino 
A Copa da vodca

O novo homem

2.2. Edição de 9 de abril de 2018

O Mantega deles

O poder da bola

Portas abertas e fechadas aos imigrantes

Os pesos do mundo

2.3. Edição de 16 de abril de 2018

Personagem da Semana - Mark Zuckerberg

Morte da democracia

Sem poder e no xilindró

Como a tecnologia ameaça a democracia

2.4. Edição de 23 de abril de 2018

A cápsula do tempo da New York

Bom populismo é um Oximoro?

A marcha dos desesperados

Por que os ataques à Síria?

Paraguai e Venezuela vão às urnas

O homem detestado por Hilary e por Trump

2.5. Edição de 30 de abril de 2018

Os intérpretes do poder

O liberalismo econômico em xeque

Os arrependidos do Brexit

O novo contra a velha mesma coisa

2.6. Edição de 7 de maio de 2018

Uma receita para curar a miopia democrática

7 perguntas para Chris Lehane

Paris 1968-2018

Vai pro trono ou não vai?

Nos embalos do K-pop

Como a Síria chegou a este ponto

2.7 Edição de 14 de maio de 2018

Personagem da Semana - Doria Ragland

Cohn-Bendit, o legado de 1968 e o futebol

Como caçar um doleiro

Ninalee Allen Craig 1927-2018

Dame Lechugas

Por uma cabeça, ou ninguém é dono de seu destino

O Vale do Silício chinês

Um bárbaro para chamar de seu

2.8. Edição de 21 de maio de 2018

Tragédia e retorno

A arte dos nomes 
Tchiéne una sacuela

Batendo Panelas

Tom Wolf 1930-2018

$\mathrm{O}$ ativismo nerd de Childish Gambino

2.9. Edição de 28 de maio de 2018

A obra inacabada de Alberto Dines

14 perguntas para Amy Webb

Duas décadas de absurdos

Philip Roth 1933-2018

A ascensão dos selvagens

2.10. Edição de 4 de junho de 2018

Um inédito duelo de extremos

Aborto, assunto de homens

2.11. Edição de 11 de junho de 2018

Fora da festa

Pampas em transe

Os papagaios e nós

2.12. Edição de 18 de junho de 2018

Personagem da semana - Trump-Kim

A imprensa como sarcedócio

O terror está no detalhe

6 perguntas para Miroslav Volf

Um dinossauro na Sala

2.13 Edição de 28 de junho de 2018

Grito político, silêncio infame

Crianças apartadas dos pais

A Guatemala é aqui

Por que o Brasil passou a comprar reais no exterior Aquilo que a Rússia produziu de melhor

11 perguntas para Manuel Castells

Lorotas latinas

3. Planilhas

3.1. Menções por Estados (Revista Época)

$\begin{array}{ll}\text { Palestina } & 2 \text { contextos } \\ \text { Reino Unido } & 1 \text { contexto } \\ \text { França } & 8 \text { contextos } \\ \text { Israel } & 4 \text { contextos } \\ \text { Estados Unidos } & 28 \text { contextos } \\ \text { China } & 7 \text { contextos } \\ \text { Argentina } & 11 \text { contextos } \\ \text { Brasil } & 16 \text { contextos }\end{array}$




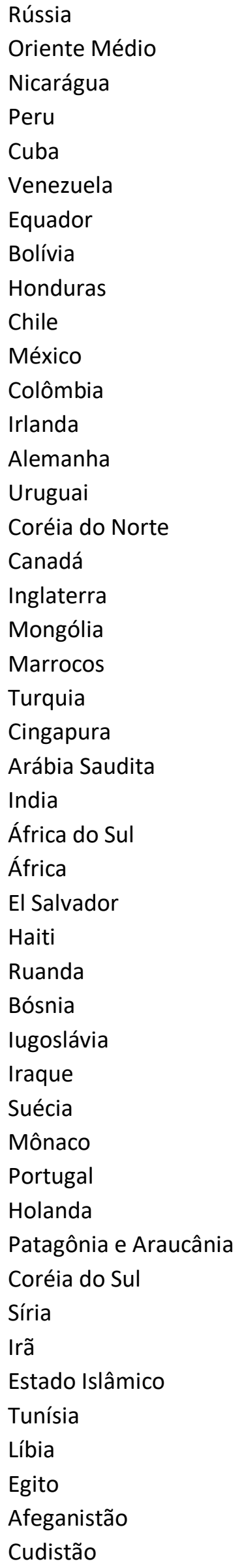

10 contextos

1 contexto

5 contextos

3 contextos

1 contexto

7 contextos

2 contextos

2 contextos

7 contextos

2 contextos

4 contextos

1 contexto

2contextos

4 contextos

3 contextos

1 contexto

2 contextos

7 contextos

1 contexto

1 contexto

5 contextos

1 contexto

2 contextos

1 contexto

1 contexto

1 contexto

5 contextos

2 contextos

1 contexto

1 contexto

1 contexto

2 contextos

1 contexto

1 contexto

3 contextos

1 contexto

1 contexto

2 contextos

2 contextos

2 contextos

1 contexto

1 contexto

2 contextos

1 contexto

1 contexto

1 contexto 


$\begin{array}{ll}\text { Jordânia } & 1 \text { contexto } \\ \text { Líbano } & 2 \text { contextos } \\ \text { Panamá } & 2 \text { contextos } \\ \text { Paraguai } & 3 \text { contextos } \\ \text { Suíça } & 1 \text { contexto } \\ \text { Itália } & 3 \text { contextos } \\ \text { Hong Kong } & 1 \text { contexto } \\ \text { Guatemala } & 3 \text { contextos } \\ \text { Espanha } & 1 \text { contexto } \\ \text { Moçambique } & 1 \text { contexto } \\ \text { Polônia } & 1 \text { contexto } \\ \text { Hungria } & 2 \text { contextos } \\ \text { Geral } & 1 \text { contexto } \\ \text { Filipinas } & 1 \text { contexto } \\ \text { Bangladesh } & 1 \text { contexto } \\ \text { Mianmar } & 1 \text { contexto } \\ \text { Taiwan } & 1 \text { contextos } \\ \text { Total } & 70 \text { países mencionados }\end{array}$

3.2. Menções por assuntos da agenda internacional (Revista Época)

Saúde

Democracia, Política Interna e Externa

Segurança Interna e Externa

Direitos Humanos, Liberdade e Imigrações

Meio Ambiente

Religião

Cooperação, Economia e Desenvolvimento
1 contexto

28 contextos

21 contextos

24 contextos

1 contexto

1 contexto

14 contextos

\subsection{Contribuições dos profissionais (Revista Época)}

Salem H. Nasser

Ian Lya (Matheus Rocha)

Ariel Palacios

Janaína Figueiredo

Edward Pimenta

Paulo Roberto Pires

Helio Gurovitz

Henrique Gomes Batista

Ruan de Sousa Gabriel

Paula Soprana

Laurent Telo (Dorotheé de Bruchard)

Thiago Mattos Moreira

Andrew Tabler (Mariana Nântua) 1

Mariana Gonçalves $\quad 1$

Alessandro Giannini 1 
Chico Otávio 1

Monica de Bolle $\quad 6$

Vivian Oswald $\quad 1$

Conrado Heibner Mendes 1

Karen Abbott (Mariana Nântua) 1

Fernando Eichenberg $\quad 1$

Heloisa Traiano 1

Lucilia Soares $\quad 1$

Editorial 1

Guilherme Evelin 1

Bernardo Mello $\quad 1$

Pedro Doria $\quad 1$

Claudia Antunes $\quad 1$

Denise Chrispim Marin $\quad 1$

Claudia Sarmento $\quad 1$

Total 64

3.5. Menções por Estados (Revista Veja)

Ucrânia

Itália

Reino Unido (Inglaterra)

Síria

Coréia do Norte

Estados Unidos

Cuba

Europa (Geral)

Rússia

América Latina (Geral)

China

India

Brasil

Quênia e Etiópia (África)

Estado Islâmico e Iraque

Global

Peru

Venezuela

Vaticano

Vietnã

Tchecoslováquia

França

Alemanha

Coréia do Sul

Colômbia

Chile

Turquia
1 reportagem

4 reportagens

3 reportagens

5 reportagens

5 reportagens

32 reportagens

1 reportagem

2 reportagens

4 reportagens

1 reportagem

6 reportagens

1 reportagem

8 reportagens

1 reportagem

2 reportagens

1 reportagem

2 reportagens

4 reportagens

2 reportagens

1 reportagem

1 reportagem

2 reportagens

2 reportagens

2 reportagens

2 reportagens

2 reportagens

1 reportagem 
Polônia

África

Equador

Argentina

México

África do Sul

Israel
1 reportagem

1 reportagem

1 reportagem

2 reportagens

1 reportagem

1 reportagem

1 reportagem

3.6. Menções aos assuntos da agenda internacional (Revista Veja)

Saúde

Democracia, Política Interna e Externa

Segurança Interna e Externa

Direitos Humanos e Imigrações

Meio Ambiente

Religião

Cooperação, Economia e Desenvolvimento
1 contextualização

22 contextualizações

26 contextualizações

7 contextualizações

10 contextualizações

3 contextualizações

12 contextualizações

\subsection{Contribuições dos profissionais (Revista Veja)}

Duda Teixeira

Diogo Schelp

Maria Laura Conineu

Macelo Sakate

Leonardo Coutinho

Adriana Dias Lopes

Maria Clara Vieira

Luíza Queiroz

Felipe Conazza

Daniel Bermasco, Thiago Bronazzo e Eduardo Gonçalves

Marcela Mattos, Robson Bonin, Sofia Fernandes, Laryssa

Borges

Rubens Ricupero (Embaixador)

Lizia Bydlowski

Bianca Alvarenga

Ana Clara Costa

Vilma Gryzinksy

Luisa Bustamante

André Lahóz Mendonça de Barros

André Lopes

Tatiana Babadobulos

Fausto Godoy (Embaixador)

Thaís Botelho

Giuliano Guandalini

Jennifer Ann Thomas
16 reportagens

15 reportagens

3 colunas

5 reportagens

3 reportagens

1 reportagem

1 reportagem

2 reportagens

2 reportagens

1 reportagem

1 reportagem

1 coluna grande

1 reportagem

1 reportagem

1 reportagem

2 colunas

1 reportagem

1 coluna

3 reportagens

1 reportagem

1 coluna grande

1 reportagem

2 reportagens

3 reportagens 